\title{
基于多准则决策的长江经济带国土空间 脆弱性与恢复力研究
}

\author{
张正昱 ${ }^{1}$, 金 贵 ${ }^{2,3}$, 郭柏枢 ${ }^{1}$, 董 寅 ${ }^{4}$, 陈 坤 ${ }^{1}$ \\ (1. 湖北大学资源环境学院, 武汉 $430062 ; 2$. 华中师范大学城市与环境科学学院, 武汉 430079; \\ 3. 中国科学院地理科学与资源研究所, 北京 100101 ; 4. 中国地质大学 (武汉)公共管理学院,武汉 430074)
}

\begin{abstract}
摘要: 科学评估国土空间脆弱性与恢复力并解释其时空分布特征, 能为国土空间开发与保护 相关决策提供参考。采用综合指数法和有序加权平均 (Ordered Weighted Averaging, OWA)法 分别评价和模拟长江经济带市域国土空间脆弱性及国土空间恢复力, 并对二者的组合情况进 行综合分析。结果表明: (1)2008-2017年间长江经济带国土空间脆弱性指数有明显下降趋势, 累计下降率为 $16.49 \%$, 脆弱性指数从西向东逐步下降; (2)长江经济带“生态优先型” “维持现状 型” “开发优先型”政策情景下国土空间恢复力分别处于较高(占 $47.22 \%$ )、中等(占 35.19\%)、低 恢复力 (占 $99.07 \%$ ) 水平; (3) 长江经济带国土空间以低脆弱性一中等恢复力、低脆弱性一较低 恢复力为主导, 占 $30.63 \%$, 国土空间整体脆弱性低,恢复力处于较低至中等水平。
\end{abstract}

关键词：长江经济带; 国土空间;脆弱性评价; 恢复力评价; OWA方法

地理结构的先天脆弱性、人类经济活动对地球表层的剧烈扰动、城镇化与乡村振兴 战略目标等国情，倒逼我国进行国土空间“整体保护、系统修复与综合治理” ${ }^{[1]}$ 。实现国 土空间整体保护、系统修复与综合治理作为健全国土空间开发保护制度的基础，前提是 充分掌握国土空间本底特性。脆弱性和恢复力反映了国土空间本底特征和利用状况, 开 展国土空间脆弱性和恢复力评价与调控研究对区域空间结构优化与功能提升具有重要意义。

学术界对脆弱性与恢复力开展的有关研究内容丰富、方法多元、尺度多维。研究内 容大多关注复杂系统的脆弱性或恢复力, 如生态系统等 ${ }^{[2-4]}$ 、城市或乡村系统 ${ }^{[-7]}$ 、土地系 统 ${ }^{[8,9]}$ 、粮食安全系统 ${ }^{[10]}$ 等, 并逐渐扩展到关注生态或社会系统与脆弱性或恢复力的耦合 情况 ${ }^{[11,12]}$ 。研究方法多为知识驱动与数据驱动的综合评价方法, 如综合指数法 ${ }^{[13,14]}$ 、主成 分分析 ${ }^{[15]}$ 、OWA 方法 ${ }^{[16]}$ 等。研究尺度涉及国家、省、市或县域、流域、社区等各类范 围, 通过不同尺度脆弱性或恢复力评价指标体系构建 ${ }^{[17-19]}$ 来探寻脆弱性和恢复力分析 框架。

总体而言, 尽管针对不同研究对象的脆弱性或恢复力评价已经广泛开展, 但将脆弱 性和恢复力关联起来进行综合分析的案例并不多见。有学者运用脆弱性与恢复力评估函 数模型量化人地系统脆弱性一恢复力指数 ${ }^{[20]}$, 在用脆弱性一恢复力整合分析解构人地关 系演化路径及作用机制方面做了有益探索。而国土空间结构优化与功能提升的现实需求

收稿日期：2019-07-26; 修订日期：2019-10-21

基金项目：国家自然科学基金项目（71974070，41501593); 国家重点研发计划项目（2016YFA0602500）；教育部人 文社会科学研究基金项目（19YJCZH068）

作者简介：张正昱（1996- )，男，湖南益阳人，硕士，研究方向为国土空间优化管理。

E-mail: zzy_simlab@163.com

通讯作者：金贵（1986-)，男，江苏邳州人，博士，副教授，研究方向为国土资源评价与国土空间优化管理。

E-mail: jingui@igsnrr.ac.cn 
使得国土空间脆弱性和恢复力的综合研究变得更加迫切。基于此, 本文以长江经济带为 典型研究区开展国土空间脆弱性与恢复力评价, 并开展情景模拟和综合分析, 以期为长 江经济带国土空间科学开发与合理利用提供参考。

\section{1 研究方法与数据来源}

\section{1 研究区概况}

长江经济带国土面积约 205 万 $\mathrm{km}^{2}$ ，涉及上海、浙江、江苏等 9 省 2 市（图 1)。一般 将长江经济带分为上游、中游、下游三个区域，上游地区包括云南、贵州、四川和重庆 的 33 个城市; 中游地区包括湖北、湖南和江西的 36 个城市; 下游地区包括浙江、安徽、 江苏和上海的 41 个城市 ${ }^{[2]}$ 。长江经济带城镇化的快速推进在促进区域发展的同时，也带 来了水污染、水土流失、生态环境退化等现实问题，为促进长江经济带的科学发展，国 家提出 “共抓大保护, 不搞大开发” 的重要思想, 明确了生态优先、绿色发展的总体战 略。在推进长江经济带绿色发展的科学决策下, 国土空间合理开发和保护尤为重要, 关 键在于查明国土空间脆弱性, 提高系统恢复能力。因此, 本文将长江经济带作为研究 区，评价市域单元国土空间脆弱性，模拟不同情景下的国土空间恢复力，服务于长江经 济带国土空间开发保护决策。

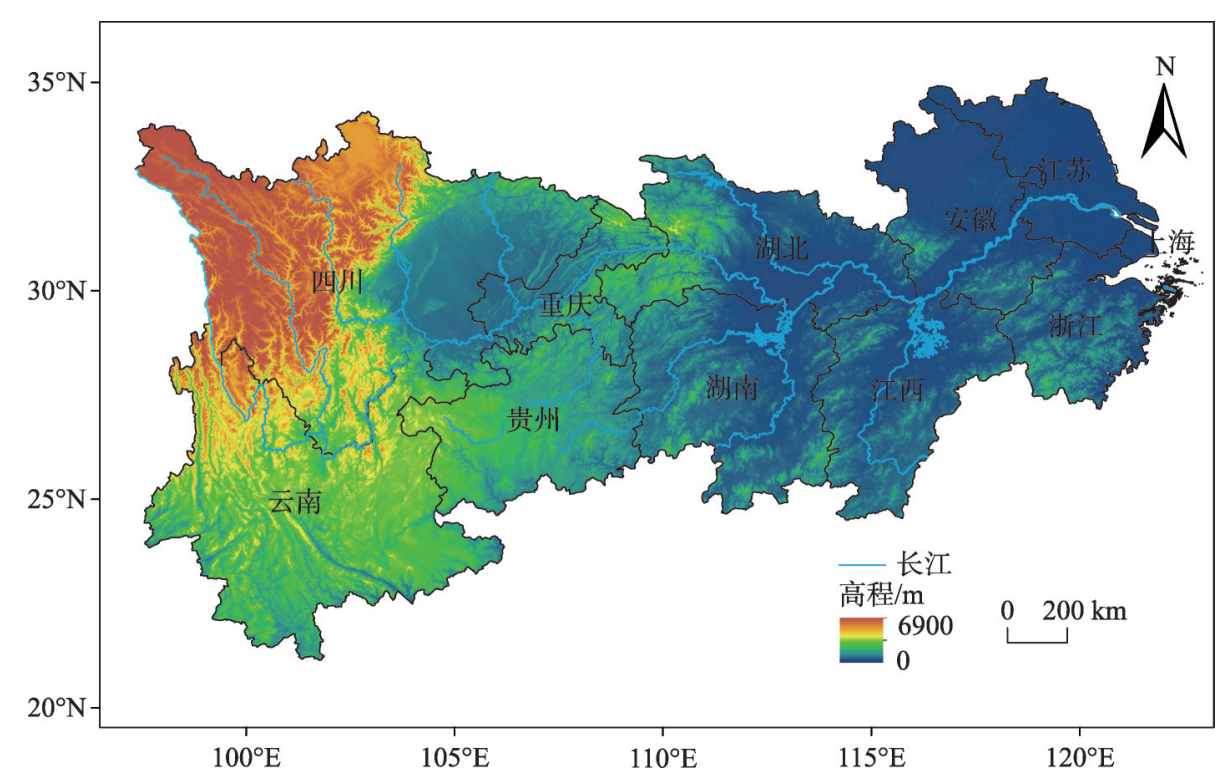

图 1 长江经济带区位

Fig. 1 The location of the Yangtze River Economic Belt

\section{2 数据来源与处理}

各省（市、区）行政边界来自 $1: 400$ 万国家基础地理信息数据库（https:// www.resdc.cn) ; 相对湿度栅格数据源于国家地球系统科学数据共享服务平台 (http://www.geodata.cn/data /publisher.html), 年平均气温、年平均降水量、植被指数、净第一生产力和 DEM 栅格数据源于中国科学院资源环境科学数据中心（http://www.resdc.cn /data.aspx? DATAID $=257$ ), 由于用来计算的栅格像元大小不一致, 为减少统计误差, 将以上栅格数 
据的空间分辨率统一重采样为 $1 \mathrm{~km}$, 对重采样后的栅格数据进行分区统计并求各地级市 平均值; 碳排放量数据采用已有能源统计资料和夜间灯光数据模拟反演核算，具体方法 参见 $\mathrm{Su}$ 等 ${ }^{[22]}$ 的研究成果; 化肥使用量数据源于 《中国区域经济统计年鉴》; 行政区域土 地面积、年末人口数和财政收人等其他数据源于 《中国城市统计年鉴》。为消除指标数据 量纲不一致问题, 评价前先对原始数据进行标准化处理。对正、负向指标采用极差标准 化方法, 适度指标（即指标数值处于某一适度值时最好）采用模糊隶属度函数法进行无 量纲化处理 ${ }^{[23]}$ 。

\section{3 指标选取}

本文采用VSD（Vulnerability Scoping Diagram）模型，从暴露度、敏感性和适应能力 三个维度构建指标，来描述国土空间开发利用过程中国土空间的脆弱性。在国土空间利 用过程中，最表象的是国土空间暴露程度。国土空间始终面临着人类活动的干扰，这种 干扰的大小反映了国土空间暴露度的大小, 暴露度越大, 国土空间脆弱性越大。因为暴 露度主要反映了人类活动的干扰，所以衡量暴露度主要考虑人口分布和工业生产方面的 指标。国土空间开发利用过程中，国土空间自然要素的特征决定了其敏感性。敏感性反 映了自然环境特征对国土空间开发利用产生的影响，敏感性越大，国土空间脆弱性越 大, 因为敏感性主要强调自然环境特征的影响, 所以衡量敏感性主要选取气候、地形等 方面的指标。国土空间对于开发利用过程中人类活动造成的干扰具有适应和调整能力 ${ }^{[24]}$, 这种能力主要体现在经济社会发展水平和环保投入等方面, 适应能力越大, 国土空间脆 弱性就越小。因为适应能力主要反映经济社会发展水平和环保力度, 所以在衡量适应能 力时主要选取体现经济发展水平和环境保护力度的指标。国土空间脆弱性指标体系中各 指标的具体含义见表 1 。

国土空间面对风险变化与干扰的恢复力来自于系统的内部特征，其内部社会、经 济、环境要素间的耦合与外在环境相互作用构成恢复力, 故本文从社会、经济、环境系

\section{表 1 国土空间脆弱性评价指标体系}

Table 1 The assessment index system of land spatial vulnerability

\begin{tabular}{|c|c|c|c|c|c|}
\hline 准则层 & 要素层 & 指标层 & 准则权重 & 指标指向 & 指标含义 \\
\hline \multirow[t]{4}{*}{ 暴露度 } & \multirow[t]{2}{*}{$\begin{array}{l}\text { 人类活动 } \\
\text { 强度 }\end{array}$} & 人口密度/(人/km²) & 0.0631 & + & $\begin{array}{l}\text { 反映人类分布的密集程度对国土空间造成的 } \\
\text { 压力与扰动 }\end{array}$ \\
\hline & & 碳排放量/万 t & 0.0543 & + & $\begin{array}{l}\text { 反映温室气体排放量变化对区域气温造成的 } \\
\text { 影响 }\end{array}$ \\
\hline & \multirow{2}{*}{$\begin{array}{l}\text { 工业生产 } \\
\text { 干扰强度 }\end{array}$} & 工业废水排放量/万 $\mathrm{t}$ & 0.1153 & + & 反映人类工业活动造成的水体污染情况 \\
\hline & & 工业二氧化硫排放量/t & 0.0464 & + & 反映人类工业活动造成的大气污染状况 \\
\hline \multirow[t]{4}{*}{ 敏感性 } & \multirow[t]{2}{*}{ 气候条件 } & 年平均气温 $\left(0.1^{\circ} \mathrm{C}\right)$ & 0.0224 & \pm & 反映系统本身温度要素变化产生的影响 \\
\hline & & 年平均降水量 $(0.1 \mathrm{~mm})$ & 0.0365 & \pm & 反映系统本身降水要素变化产生的影响 \\
\hline & \multirow[t]{2}{*}{ 地形条件 } & 坡度/() & 0.0864 & + & 反映系统受坡度影响的程度 \\
\hline & & 高程/m & 0.0763 & \pm & 反映系统受海拔影响的程度 \\
\hline \multirow[t]{4}{*}{ 适应能力 } & \multirow{2}{*}{$\begin{array}{l}\text { 经济社会 } \\
\text { 发展水平 }\end{array}$} & 人均 $\mathrm{GDP} /$ 元 & 0.2171 & - & 反映地区经济能够处理、适应胁迫的能力 \\
\hline & & $\begin{array}{l}\text { 第三产业增加值 } \\
\text { 占 GDP 比例 } / \%\end{array}$ & 0.1172 & - & 反映产业结构对胁迫的处理、适应能力 \\
\hline & \multirow[t]{2}{*}{$\begin{array}{l}\text { 生态环境 } \\
\text { 保护 }\end{array}$} & $\begin{array}{l}\text { 生活垃圾无害化 } \\
\text { 处理率/\% }\end{array}$ & 0.1242 & - & 反映对废弃物污染的处理能力 \\
\hline & & 化肥使用减少量/万 $\mathrm{t}$ & 0.0408 & - & 反映对农业污染物的控制能力 \\
\hline
\end{tabular}


统恢复力三个维度构建指标体系来评价国土空间恢复力。

社会系统恢复力是指国土空间的社会子系统面对风险与扰动的恢复能力，社会系统 的人口增长率过高会导致失业率上升、居住环境恶化等各种社会问题，从而使恢复力降 低, 反之, 则恢复力升高。年末金融机构存款余额反映社会存储对外部打击或干扰的承 受能力，人均财政支出反映政府财政在系统承受外部打击或干扰时的应对能力，这两个 指标的值越大，则恢复力越强。

经济系统恢复力是指国土空间的经济子系统对风险与扰动的恢复能力，其指标选取 反映系统的经济投人、政府财政、社会消费等情况，指标值越大，则恢复力越大。

环境系统恢复力是指国土空间的环境子系统对风险与扰动的恢复能力，净第一性生 产力和植被覆盖指数反映系统的植被生长与覆盖情况, 指标值越大, 恢复力越大。而相 对湿度反映系统在外部干扰下维持水热平衡的能力, 属于适度指标, 指标越接近于适度 值, 恢复力越大。

国土空间恢复力评价指标体系中各指标具体含义见表 2 。

表 2 国土空间恢复力评价指标体系

Table 2 The assessment index system of land spatial resilience

\begin{tabular}{|c|c|c|c|c|}
\hline 准则层 & 指标层 & 准则权重 & 指标指向 & 指标含义 \\
\hline 社会系统 & 人口自然增长率/\%o & 0.021 & - & 反映系统人口增速变动对恢复力的影响 \\
\hline \multirow[t]{2}{*}{ 恢复力 } & 年末金融机构存款余额/万元 & 0.0725 & + & 反映社会存储对外部打击或干扰的承受能力 \\
\hline & 人均财政支出/元 & 0.0838 & + & $\begin{array}{l}\text { 反映政府在人类社会承受外部对系统打击或干 } \\
\text { 扰时的应对能力 }\end{array}$ \\
\hline 经济系统 & 固定资产投资总额/万元 & 0.1593 & + & 反映经济投人对外部干扰的承受能力 \\
\hline \multirow[t]{2}{*}{ 恢复力 } & 财政收人/万元 & 0.2442 & + & 反映政府在风险干扰下的调整和适应能力 \\
\hline & 社会消费品零售总额/万元 & 0.0582 & + & 反映消费在外部干扰下的维持能力 \\
\hline 环境系统 & 净第一性生产力/(g C/m²) & 0.123 & + & 反映植物的生长状况和对外部干扰的反应 \\
\hline \multirow[t]{2}{*}{ 恢复力 } & 植被覆盖指数 & 0.1927 & + & 反映系统植被覆盖度在外界干扰下的恢复能力 \\
\hline & 相对湿度/\% & 0.0453 & \pm & 反映系统在外部干扰下维持水热平衡的能力 \\
\hline
\end{tabular}

国土空间脆弱性和国土空间恢复力的差异性体现在研究重点和目的上，国土空间脆 弱性的研究重点在于对外部风险和扰动的暴露度、敏感性的辨识, 研究目的在于提升个 体、群体或区域的适应能力。国土空间恢复力的研究重点在于非线性动力、阈值和不确 定性, 研究目的是系统的可持续管理。脆弱性和恢复力的共性体现在应对压力或变化的 适应能力方面。因此，国土空间脆弱性和恢复力是两个不同但互补的概念，二者相辅相 成，两者的评估结果共同反映了国土空间本底特征和利用状况。

国土空间脆弱性主要面向国土空间开发利用过程，国土空间开发占用和破坏国土空 间生态用地，会使得国土空间脆弱性进一步增大，而国土空间脆弱性大小又反作用于国 土空间开发利用活动。国土空间开发利用的难度越大, 越要注意控制好开发力度, 对国 土空间的脆弱因子进行保护和修复。而国土空间恢复力主要面向国土空间保护与修复过 程，对国土空间保护与修复会提高国土空间恢复能力，同时，国土空间的经济、社会、 环境系统发展越好，国土空间恢复力越高，进行国土空间保护和修复的难度就越小。

\section{4 研究方法}

\subsection{1 综合指数法}

利用综合指数法进行国土空间脆弱性指数计算, 将不同性质量纲指标无因次化, 转 
化为标准形式, 将转化的实数计算成综合指数 ${ }^{[25]}$, 指标体系权重采用层次分析法求得, 各指标准则权重见表 1 , 综合指数法表达式为:

$$
S_{i}=\sum_{j=1}^{n} P_{j} \times W_{j}
$$

式中: $S_{i}$ 为国土空间脆弱性指数, 评价单元 $i=1,2, \cdots, n ; P_{j}$ 为第 $j$ 个评价因子得分值, 评 价因子 $j=1,2, \cdots, n ; W_{j}$ 为第 $i$ 个评价单元的第 $j$ 个评价因子权重。

\subsubsection{OWA 方法}

参考 Yager ${ }^{[26]}$ 的空间多准则评价过程, 将语言量化算子和 OWA 方法结合, 利用AHP （Analytic Hierarchy Process）方法计算准则权重（表3）并对其进行排序，通过给定决策 风险确定次序权重, 对准则属性值和次序权重进行线性组合从而得到评价结果, 公式 如下:

$$
O W A_{i}=\sum_{j=1}^{n}\left(\frac{u_{i} v_{j}}{\sum_{j=1}^{n} u_{i} v_{j}}\right) Z_{i j}
$$

式中: $Z_{i j}$ 为第 $i$ 个像元中第 $j$ 项指标对应的属性值; $u_{i}$ 为准则权重, $u_{i} \in[0,1]$, 且 $u_{1}+u_{2}+$ $u_{3}+, \cdots,+u_{n}=1 ; v_{j}$ 为次序权重, $v_{j} \in[0,1]$, 且 $v_{1}+v_{2}+v_{3}+, \cdots,+v_{n}=1$ 。

OWA算法核心在于对指标按照属性重要性重新排序，对不同排序位次赋子不同次序 权重。选用计算量小且易于理解的模糊量化模型 ${ }^{[27]}$ 计算次序权重，计算公式如下:

$$
v_{j}=\left(\sum_{k=1}^{j} w_{k}\right)^{\alpha}-\left(\sum_{k=1}^{j-1} w_{k}\right)^{\alpha}
$$

式中： $\alpha$ 为决策风险系数, 取决于决策风险, 取值范围在 0 到 $\infty$ 之间; $w_{k}$ 为指标重要等 级，依据指标数值大小确定，用以下公式计算:

$$
w_{k}=\frac{n=r_{k}+1}{\sum_{l}^{k}\left(n-r_{k}+1\right)}(k=1,2, \cdots, n)
$$

式中: $n$ 表示指标总个数; $r_{k}$ 为根据指标数值大小对指标重要性的取值, 最大值取 1 , 次 大取 2 , 最小取 $n$ 。

运用模糊量化方法对 7 种不同决策风险系数下的次序权重进行计算，运算结果见表 3 。

在决策者无偏好（ $\alpha=1 ）$ 状况下，评价过程相当于运用综合指数法，直接使用准则权 重进行评价。若 $\alpha<1$, 则最重要的属性位序权重越大, 评价者对指标的属性持乐观态度, 只需要重要的前几层算子即可判定。若 $\alpha>1$, 则越重要的属性位序权重越小, 评价者对指 标的属性持悲观态度，后面几层不重要的算子更被重视。本文中，“乐观”表明评价者认 为社会、经济和环境系统指标能够影响国土空间恢复力，而 “悲观” 表明评价者不认为 社会、经济和环境系统指标能够影响国土空间恢复力。

\section{2 结果分析}

\section{1 长江经济带国土空间脆弱性分析}

由综合指数法计算得到 2008-2017 年长江经济带国土空间脆弱性指数（图 2)。根据 期中 2013 年脆弱性指数, 通过自然断点法将其从高到低分为高、较高、中等、较低、低 
表 3 国土空间恢复力评价指标次序权重

Table 3 The index order weight of land spatial resilience evaluation

\begin{tabular}{cccccccc}
\hline 位序权重 & $\begin{array}{c}\alpha=0.0001 \\
\text { 最乐观 }\end{array}$ & $\begin{array}{c}\alpha=0.1 \\
\text { 乐观 }\end{array}$ & $\begin{array}{c}\alpha=0.5 \\
\text { 较乐观 }\end{array}$ & $\begin{array}{c}\alpha=1 \\
\text { 无偏好 }\end{array}$ & $\begin{array}{c}\alpha=2 \\
\text { 较悲观 }\end{array}$ & $\begin{array}{c}\alpha=10 \\
\text { 悲观 }\end{array}$ & $\begin{array}{c}\alpha=1000 \\
\text { 最悲观 }\end{array}$ \\
\hline$W_{1}$ & 1.000 & 0.803 & 0.333 & 0.111 & 0.012 & 0.000 & 0.000 \\
$W_{2}$ & 0.000 & 0.058 & 0.138 & 0.111 & 0.037 & 0.000 & 0.000 \\
$W_{3}$ & 0.000 & 0.036 & 0.106 & 0.111 & 0.062 & 0.000 & 0.000 \\
$W_{4}$ & 0.000 & 0.026 & 0.089 & 0.111 & 0.086 & 0.000 & 0.000 \\
$W_{5}$ & 0.000 & 0.021 & 0.079 & 0.111 & 0.111 & 0.003 & 0.000 \\
$W_{6}$ & 0.000 & 0.017 & 0.071 & 0.111 & 0.136 & 0.015 & 0.000 \\
$W_{7}$ & 0.000 & 0.015 & 0.065 & 0.111 & 0.160 & 0.064 & 0.000 \\
$W_{8}$ & 0.000 & 0.013 & 0.061 & 0.111 & 0.185 & 0.227 & 0.000 \\
$W_{9}$ & 0.000 & 0.012 & 0.057 & 0.111 & 0.210 & 0.692 & 1.000 \\
\hline
\end{tabular}

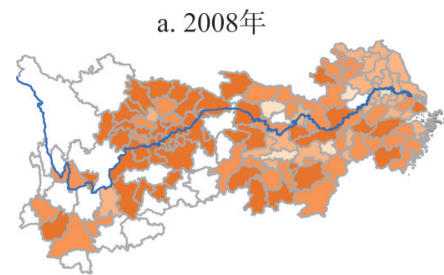

d. 2011年

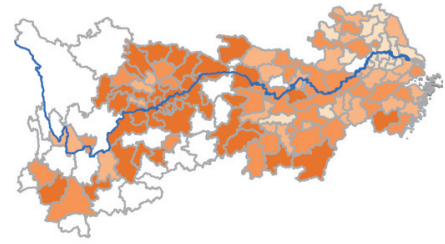

g. 2014年

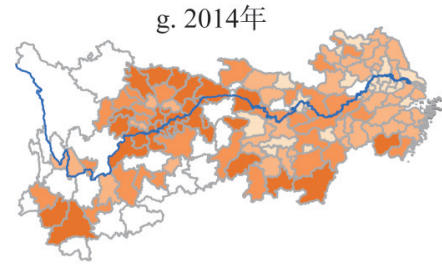

j. 2017年

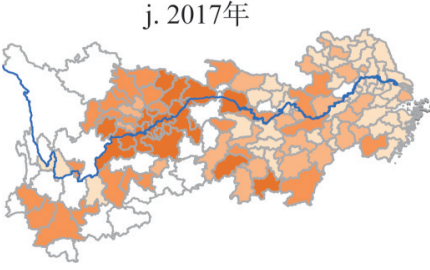

b. 2009年

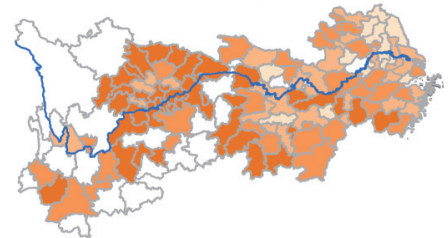

e. 2012 年

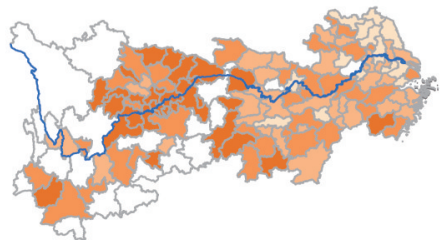

h. 2015年

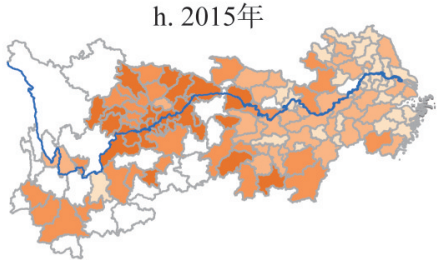

脆弱性分级

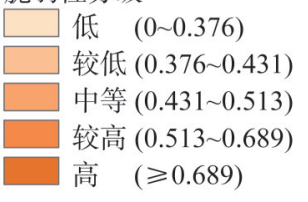

c. 2010 年

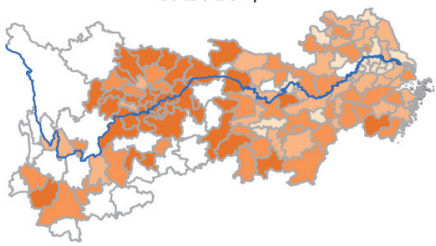

f. 2013年

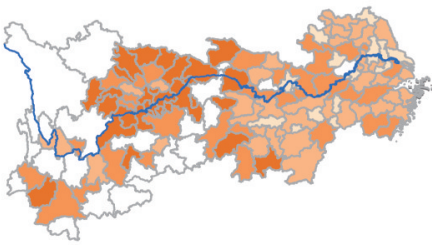

i. 2016年

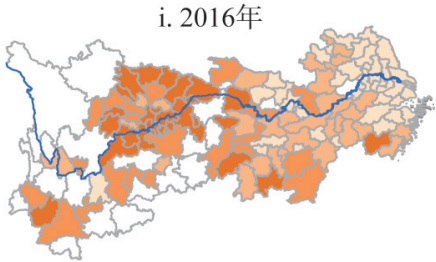

一长汀

样本未覆盖区

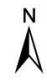

$0 \quad 500 \mathrm{~km}$

图 2 长江经济带国土空间脆弱性指数

Fig. 2 The land spatial vulnerability index in the Yangtze River Economic Belt

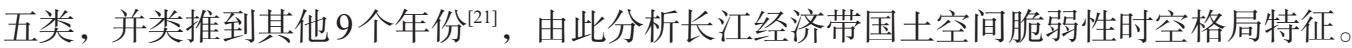

从时间角度看，长江经济带2008年、2011年、2014年、2017年国土空间脆弱性指数 均值分别为 $0.485 、 0.461 、 0.435$ 和 0.405 ，其 $2008-2017$ 年间累计下降率为 $16.49 \%$ ，呈明 显下降趋势，分析脆弱性指数指标数值变化可知，这种趋势与人均GDP、第三产业增加 
值、生活垃圾无害化处理率等负向指标上升有关。从空间格局看，长江经济带国土空间 脆弱性呈现集聚分布, 脆弱性高的地区主要分布于长江中上游的重庆、四川、云南等 地。长江上游、中游、下游的脆弱性指数均值分别为 $0.51 、 0.441 、 0.397$, 呈从西向东 递减趋势。

\section{2 基于多情景方案的长江经济带国土空间恢复力分析}

在充分调查市域经济社会发展情况后，设置三种政策情景模拟长江经济带2017年国 土空间恢复力, $\alpha=1$ 时长江经济带社会、经济发展维持常态, 定义为维持现状型情景; $\alpha=0.8$ 表示重视环境保护治理与投人，降低对能源依赖的情景，定义为生态优先型情景; $\alpha=3$ 表示注重经济发展而减少对生态环境、自然灾害等问题考虑的情景，定义为开发优 先型情景。通过自然断点法将恢复力指数从高到低分为高、较高、中等、较低、低五 类，具体评价结果见图3。

结合图 3 分析三种情景下长江经济带国土空间恢复力, 乐观情景下, 恢复力低值部 分和高值部分出现分化, 空间分异特征明显; 悲观情景下, 部分重要指标未得到充分反 映，恢复力评价可信度降低。“生态优先型” 政策情景下，恢复力处于较高水平的市域占 比最大, 占 $47.22 \%$, 国土空间呈现出一定的开发潜力; “维持现状型” 政策情景的评价 结果反映 2017 年长江经济带恢复力现实状况，该情景下长江经济带恢复力处于中等水平 的市域最多，占 $35.19 \%$ ，市域恢复力基本处于中等水平; “开发优先型” 政策情景下低 恢复力市域占比达 $99.07 \%$ ，区域整体呈低恢复力状态。

a. 生态优先型情景

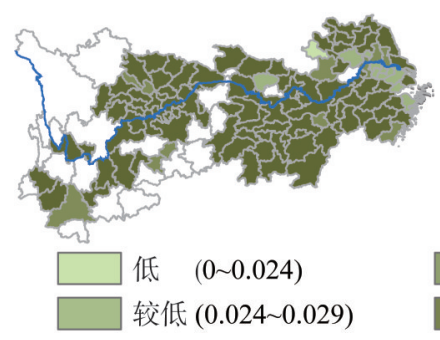

b. 维持现状型情景

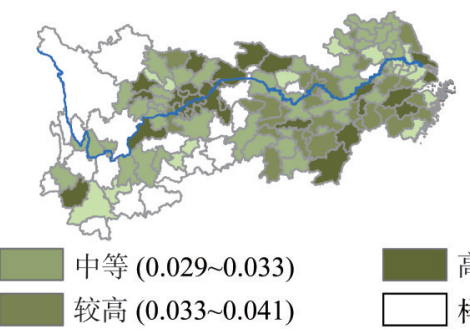

c. 开发优先型情景

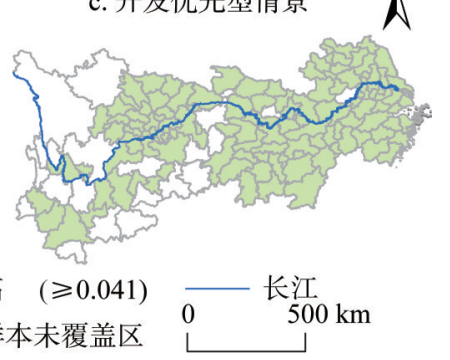

图 3 不同政策情景下长江经济带国土空间恢复力

Fig. 3 The land spatial resilience in the Yangtze River Economic Belt under different policy scenarios

\section{3 长江经济带国土空间脆弱性一恢复力综合分析}

将2017年三种情景下长江经济带脆弱性一恢复力组合情况对比后发现, “生态优先 型” 情景下以低脆弱性一较高恢复力和中等脆弱性一较高恢复力为主, 占 $33.33 \%$; “维 持现状型” 政策情景下以低脆弱性一中等恢复力和低脆弱性一较低恢复力两种状态为 主，占 $30.63 \%$; “开发优先型” 情景以低脆弱性一低恢复力为主，占 $43.52 \%$ 。说明 “生 态优先型” 情景脆弱性一恢复力组合情况最好, “维持现状型” 情景次之, “开发优先 型” 情景最差。

“维持现状型” 政策情景下以低脆弱性一中等恢复力和低脆弱性一较低恢复力状态为 主, 表明长江经济带的整体脆弱性低, 恢复力处于较低至中等水平, 对此, 需增强社 
会、经济对国土空间可持续发展的保障，加快推进国土生态修复工作实施，从而改善区 域国土空间脆弱性一恢复力状况。

进一步从流域上游、中游、下游进行分析，上游以中等脆弱性一较低恢复力和较低 脆弱性一较低恢复力主导，占 $41.94 \%$ 。由于受坡度、地形等自然条件影响，上游市域国 土空间脆弱性相对于整体偏高，而经济社会发展程度相对落后又使得其国土空间恢复力 处于较低水平, 例如昭通、遵义呈现出较高脆弱性一较低恢复力。对此, 上游地区应加 强国土综合整治与生态保护修复，坚持自然恢复为主、人工修复为辅，因地制宜发展生 产，在保护好重要生态因子的前提下进一步加强社会经济建设。

中游以低脆弱性一中等恢复力和较低脆弱性一中等恢复力为主导，占 $36.11 \%$ 。市域 系统具有较强稳定性，国土空间具有较高开发潜力，这些市域在国土空间开发时要提高 生产效率和资源利用效率，以资源高效利用提升国土空间质量，同时也要把握好开发力 度, 注重绿色发展。

下游以低脆弱性一较低恢复力和低脆弱性一中等恢复力主导，占 $48.78 \%$ 。大部分市 域呈现低脆弱性，这和长江经济带整体的情况保持一致，但部分市域应对外界扰动的恢 复力有待提高, 如徐州、淮南等市域均为低脆弱性一较低恢复力状态, 在国土开发过程 中需重视生态环境保护和修复, 修复退化及受损的山水林田湖草生态系统, 寻求国土空 间要素比配最优化，打造宜居、宜业的生活、生产空间。

\section{3 结论与讨论}

\section{1 结论}

本文采用综合指数法和 OWA 方法分别评价 2008-2017年长江经济带市域国土空间脆 弱性及 2017 年不同情景方案下国土空间恢复力, 并对长江经济带国土空间脆弱性一恢复 力进行综合分析，结果表明：

（1）2008-2017年间长江经济带国土空间脆弱性呈明显下降趋势，国土空间脆弱性指 数均值由 0.485 降至 0.405 , 累计下降率为 $16.49 \%$; 研究区国土空间脆弱性指数在空间上 呈现集聚分布, 脆弱性指数从西向东逐步下降。

（2）长江经济带 “生态优先型” “维持现状型” “开发优先型” 政策情景下国土空间 恢复力分别处于较高（占 $47.22 \%$ )、中等（占 $35.19 \%$ )、低恢复力（占 $99.07 \% ）$ 水平。

（3）长江经济带以低脆弱性一中等恢复力、低脆弱性一较低恢复力为主导, 占 $30.63 \%$ ，区域整体脆弱性低，但其恢复力有待提高。

\section{2 讨论}

本文在进行国土空间脆弱性评价时采用 VSD 模型, 从暴露度、敏感性和适应能力三 方面遴选指标，有利于更充分地反映国土空间脆弱性。国土空间恢复力评价指标体系构 建主要从国土空间社会、经济、环境三个子系统人手，实现对国土空间恢复力的刻画， 由于研究区涉及长江经济带 108 个地级市, 考虑到数据的可获取性, 本文选取 9 个典型指 标进行恢复力评价，若涉及更小尺度评价可以适当细化评价指标。

通过 OWA 方法进行国土空间恢复力评价有助于决策者更全面、科学地判断与决策, 在国土空间开发过程中，纯粹只注重社会经济或环境保护对区域而言都是不符合可持续 
发展需要的，作为决策支持应重视不同情景间组合与阈值变化的过渡 ${ }^{[28]}$ 。随着时间推

移，国土空间系统内部各因子恢复能力的变动导致国土空间系统恢复力处于动态变化之

中，进行不同政策下的恢复力评价有利于满足不同决策思路下国土空间开发布局需求。

本文基于对国土空间系统的认识，尝试探索对于国土空间脆弱性与恢复力的有效评 价方法及分析思路, 通过对脆弱性一恢复力的综合分析, 针对长江上游、中游、下游脆 弱性一恢复力组合的现实情况，提出国土空间开发和生态修复方面的具体建议。由于国 土空间系统构成和演进的复杂性, 本研究在国土空间脆弱性一恢复力综合分析理论框架 探讨上还存在不足，一个通用的国土空间脆弱性一恢复力演进理论框架与方法论体系有 待进一步探索，同时更精确的脆弱性一恢复力测度模型也亟需构建。

\section{参考文献(References):}

[1] 白中科, 周伟, 王金满, 等. 试论国土空间整体保护、系统修复与综合治理. 中国土地科学, 2019, 33(2): 1-11. [BAI Z $\mathrm{K}, \mathrm{ZHOU} \mathrm{W}$, WANG J M, et al. Overall protection, systematic restoration and comprehensive management of land space. China Land Science, 2019, 33(2): 1-11.]

[2] 王群, 陆林, 杨兴柱. 国外旅游地社会一生态系统恢复力研究进展与启示. 自然资源学报, 2014, 29(5): 894-908. [WANG Q, LU L, YANG X Z. Research progress and enlightenment of tourism socio-ecological system resilience in foreign countries. Journal of Natural Resources, 2014, 29(5): 894-908.]

[3] HOLLING C S. Resilience and stability of ecological systems. Annual Review of Ecology and Systematics, 1973, 4(1): $1-23$.

[4] SHAHBAZI F, JAFARZADEH A, SHAHBAZI M. Agro-ecological field vulnerability evaluation and climate change impacts in Souma area (Iran), using MicroLEIS DSS. Biologia, 2009, 64(3): 555-559.

[5] 方创琳, 王岩. 中国城市脆弱性的综合测度与空间分异特征. 地理学报, 2015, 70(2): 234-247. [FANG C L, WANG Y. A comprehensive assessment of urban vulnerability and its spatial differentiation in China. Acta Geographica Sinica, 2015, 70(2): 234-247.]

[6] 彭建, 刘炎序, 潘雅婧, 等. 基于景观格局一过程的城市自然灾害生态风险研究: 回顾与展望. 地球科学进展, 2014, 29(10): 1186-1196. [PENG J, LIU Y X, PAN Y J, et al. Study on the correlation between ecological risk due to natural disaster and landscape pattern-process: Review and prospect. Advances in Earth Science, 2018, 38(11): 3741-3755.]

[7] 温晓金, 刘炎序, 杨新军. 恢复力视角下生态型城市植被恢复空间分异及其影响因素: 以陕南商洛市为例. 生态学 报, 2015, 35(13): 4377-4389. [WEN X J, LIU Y X, YANG X J. A resilience-based analysis on the spatial heterogeneity of vegetation restoration and its affecting factors in the construction of eco-cities: A case study of Shangluo, Shaanxi. Acta Ecologica Sinica, 2015, 35(13): 4377-4389.]

[8] 虞燕娜, 朱江, 吴绍华, 等. 多风险源驱动下的土地生态风险评价: 以江苏省射阳县为例. 自然资源学报, 2016, 31(8): 1264-1274. [YU Y N, ZHU J, WU S H, et al. Assessment of land ecological risks driven by multi-sources: A case study of Sheyang county, Jiangsu province. Journal of Natural Resources, 2016, 31(8): 1264-1274.]

[9] 彭建, 魏海, 武文欢, 等. 基于土地利用变化情景的城市暴雨洪涝灾害风险评估: 以深圳市茅洲河流域为例. 生态学 报, 2018, 38(11): 3741-3755. [PENG J, WEI H, WU W H, et al. Storm flood disaster risk assessment in urban area based on the simulation of land use scenarios: A case of Maozhou Watershed in Shenzhen city. Acta Geographica Sinica, 2018, 38(11): 3741-3755.]

[10] 姚成胜, 殷伟, 李政通. 中国粮食安全系统脆弱性评价及其驱动机制分析. 自然资源学报, 2019, 34(8): 1720-1734. [YAO C S, YIN W, LI Z T. The vulnerability assessment and driving mechanism analysis of China's food security system. Journal of Natural Resources, 2019, 34(8): 1720-1734.]

[11] 谢盼, 王仰麟, 刘炎序, 等. 基于社会脆弱性的中国高温灾害人群健康风险评价. 地理学报, 2015, 70(7): 1041-1051. [XIE P, WANG Y L, LIU Y X, et al. Incorporating social vulnerability to assess population health risk due to heat stress in China. Acta Geographica Sinica, 2015, 70(7): 1041-1051.] 
[12] 刘炎序, 王仰麟, 彭建, 等. 耦合恢复力的林区土地生态适宜性评价: 以吉林省汪清县为例. 地理学报, 2015, 70(3): 476-487. [LIU Y X, WANG Y L, PENG J, et al. Land ecological suitability assessment for forest coupled with the resilience perspective: A case study in Wangqing county, Jilin province, China. Acta Geographica Sinica, 2015, 70(3): 476487.]

[13] 战金艳, 间海明, 邓祥征, 等. 森林生态系统恢复力评价: 以江西省莲花县为例. 自然资源学报, 2012, 27(8): 13041315. [ZHAN J Y, YAN H M, DENG X Z, et al. Assessment of forest ecosystem resilience in Lianhua county of Jiangxi province. Journal of Natural Resources, 2012, 27(8): 1304-1315.]

[14] 李文龙, 石育中, 鲁大铭, 等. 北方农牧交错带干旱脆弱性时空格局演变. 自然资源学报, 2018, 33(9): 1599-1612. [LI W L, SHI Y Z, LU D M, et al. The spatio-temporal evolution of drought vulnerability in the ecotone between agriculture and animal husbandry in the north of China. Journal of Natural Resources, 2018, 33(9): 1599-1612.]

[15] 李宏薇, 徐永亮, 许尔琪, 等. 珠江三角洲的城市灾害恢复力评估. 灾害学, 2019, 34(3): 209-215. [LI H W, XU Y L, XU E Q, et al. Urban disaster resilience assessment in the Pearl River Delta. Journal of Catastrophology, 2019, 34(3): 209-215.]

[16] 张行, 梁小英, 刘迪, 等. 生态脆弱区社会一生态景观恢复力时空演变及情景模拟. 地理学报, 2019, 74(7): 14501466. [ZHANG X, LIANG X Y, LIU D, et al. The resilience evolution and scenario simulation of social-ecological landscape in the fragile area. Acta Geographica Sinica, 2019, 74(7): 1450-1466.]

[17] LEE Y. Social vulnerability indicators as a sustainable planning tool. Environmental Impact Assessment Review, 2014, 44: 31-42.

[18] 刘小茜, 王仰麟, 彭建. 人地耦合系统脆弱性研究进展. 地球科学进展, 2009, 24(8): 917-927. [LIU X Q, WANG Y L, PENG J. Progress in vulnerability analysis of coupled human-environment system. Advances in Earth Science, 2009, 24 (8): 917-927.]

[19] 杨庚, 曹银贵, 罗古拜, 等. 生态系统恢复力评价研究进展. 浙江农业科学. 2019, 60(3): 508-513. [YANG G, CAO Y G, LUO G B, et al. Advances in ecosystem resilience assessment. Journal of Zhejiang Agricultural Sciences, 2019, 60 (3): 508-513.]

[20] 陈佳. 干旱乡村人地系统演化的脆弱性一恢复力整合研究. 西安: 西北大学, 2018. [CHEN J. The integration of vulnerability-resilience of rural human-environment system evolution: A case study of Minqin county in Gansu province. Xi'an: Northwest University, 2018.]

[21] 金贵, 邓祥征, 赵晓东, 等. 2005-2014年长江经济带城市土地利用效率时空格局特征. 地理学报, 2018, 73(7): 12421252. [JIN G, DENG X Z, ZHAO X D, et al. Spatio-temporal patterns of urban land use efficiency in the Yangtze River Economic Zone during 2005-2014. Acta Geographica Sinica, 2018, 73(7): 1242-1252.]

[22] SU Y X, CHEN X Z, LI Y, et al. China's 19-year city-level carbon emissions of energy consumptions, driving forces and regionalized mitigation guidelines. Renewable and Sustainable Energy Reviews, 2014, 35: 231-243.

[23] 陈佳, 杨新军, 尹莎, 等. 基于 VSD 框架的半干旱地区社会一生态系统脆弱性演化与模拟. 地理学报, 2016, 71(7): 1172-1188. [CHEN J, YANG X J, YIN S, et al. The vulnerability evolution and simulation of the social-ecological systems in the semi-arid area based on the VSD framework. Acta Geographica Sinica, 2016, 71(7): 1172-1188.]

[24] 李平星, 樊杰. 基于 VSD 模型的区域生态系统脆弱性评价: 以广西西江经济带为例. 自然资源学报, 2014, 29(5): 779-788. [LI P X, FAN J. Regional ecological vulnerability assessment based on VSD model: A case study of Xijiang River Economic Belt in Guangxi. Journal of Natural Resources, 2014, 29(5): 779-788.]

[25] 金贵, 王占岐, 胡学东, 等. 基于模糊证据权模型的青藏高原区土地适宜性评价. 农业工程学报, 2013, 29(18): 241250. [JIN G, WANG Z Q, HU X D, et al. Land suitability evaluation in Qinghai-Tibet Plateau based on fuzzy weight of evidence model. Transactions of the CSAE, 2013, 29(18): 241-250.]

[26] YAGER R R. On ordered weighted averaging aggregation operators in multicriteria decisionmaking. IEEE Transactions on Systems, Man, and Cybernetics, 1988, 18(1): 183-190.

[27] 张洪, 王安琦, 宋贝扬. 基于 OWA 的大理市土地生态安全评价研究. 地理科学, 2017, 37(11): 1778-1784. [ZHANG H, WANG A Q, SONG B Y. Evaluation of land ecological security in Dali city based on OWA. Scientia Geographica Sinica, 2017, 37(11): 1778-1784.] 
[28] 刘炎序, 彭建, 韩忆楠, 等. 基于 OWA 的低丘缓坡建设开发适宜性评价: 以云南大理白族自治州为例. 生态学报, 2014, 34(12): 3188-3197. [LIU Y X, PENG J, HAN Y N, et al. Suitability assessment for building land consolidation on gentle hillside based on OWA operator: A case in Dali Bai Nationality Borough in Yunnan, China. Acta Geographica Sinica, 2014, 34(12): 3188-3197.]

\title{
Research on the spatial vulnerability and resilience of land in the Yangtze River Economic Belt based on multi-criteria decision
}

\author{
ZHANG Zheng-yu', JIN Gui ${ }^{2,3}$, GUO Bai-shu', DONG Yin ${ }^{4}$, CHEN Kun ${ }^{1}$ \\ (1. Faculty of Resources and Environmental Science, Hubei University, Wuhan 430062, China; \\ 2. College of Urban and Environmental Science, Central China Normal University, Wuhan 430079, China; \\ 3. Institute of Geographic Sciences and Natural Resources Research, CAS, Beijing 100101, China; 4. School of \\ Public Administration, China University of Geosciences, Wuhan 430074, China)
}

\begin{abstract}
Scientific assessment of spatial vulnerability and resilience and analysis of its spatiotemporal distribution characteristics can provide reference for the decision- making of land spatial development and protection. The comprehensive index assessment method and the Ordered Weighted Averaging (OWA) method are used to evaluate land spatial vulnerability and to simulate the land spatial resilience at the municipal scale in the Yangtze River Economic Belt, respectively. The comprehensive analysis is used to examine the combination characteristics of land saptial vulnerability and resilience. The results showed that: (1) The spatial vulnerability index of land in the study area has a significant downward trend, and the cumulative decline rate is $16.49 \%$ from 2008 to 2017 . And the spatial vulnerability index gradually decreases from west to east. (2) Under the policy scenarios of "ecological priority", "maintenance status" and "development priority", the spatial resilience of the region is in the higher degree (47.22\%), medium degree (35.19\%) and low degree (99.07\%), respectively. (3) The land in the Yangtze River Economic Belt is dominated by the types of low vulnerabilitymoderate resilience and low vulnerability- low resilience, accounting for $30.63 \%$ of the total land area. The overall vulnerability of land is low, and its resilience is at a low to medium level.
\end{abstract}

Keywords: Yangtze River Economic Belt; land space; vulnerability assessment; resilience evaluation; Ordered Weighted Average method 